\title{
ARQUITETURA E ERGONOMIA: A ATIVIDADE COMO EIXO CONDUTOR DE PROJETO
}

\author{
ROCHA, Daniela \\ Universidade de Brasília, e-mail: arq.danielarocha@gmail.com \\ ABRAHÃO, Júlia \\ Universidade de Brasília, e-mail: julia.abrahao@gmail.com
}

\begin{abstract}
RESUMO
Os projetos arquitetônicos, sobretudo os destinados aos edifícios industriais, têm adotado como parâmetro usual de dimensionamento, critérios fixos de metragem quadrada de acordo com mobiliário ou número de ocupantes por ambiente. Projetos destinados ao uso industrial também admitem, como fio condutor para sua configuração espacial, o fluxo da produção elaborado a partir das tarefas, preterindo, assim, a variabilidade do processo produtivo e sua evolução. Esta prática torna o espaço de trabalho um ditado ao qual os funcionários devem se adaptar, impactando na produtividade e na qualidade de produção de bens e serviços, que por sua vez, geram prejuízos financeiros à instituição. Uma das problemáticas, encontrada na concepção de projeto arquitetônico, é a dificuldade de integrar, na prática, a qualidade funcional prevista em um programa de necessidades, ao projeto. De fato, é considerado como prioridade, o que é prescrito, ou seja, a tarefa, desconsiderando a atividade e as questões dela decorrentes. Nesta pesquisa propõe-se uma articulação dos conceitos de Ergonomia à prática de projeto de Arquitetura, visando uma abordagem que assuma a atividade como o elemento organizador dos componentes do espaço. Integrou-se, então, como ferramenta auxiliar de investigação a Análise Ergonômica do Trabalho no processo de elaboração do Programa de Necessidades Arquitetônico. Para tanto, foram analisadas, de forma sistemática, as atividades, inerentes às tarefas de uma indústria brasileira do ramo alimentício. Os resultados apontaram que a falta da análise das atividades gerou um fluxo desordenado na produção e um leiaute que dificulta a flexibilização dos espaços.
\end{abstract}

Palavras-chave: Arquitetura, Ergonomia, Programa de Necessidades Arquitetônico, Análise Ergonômica do Trabalho.

\begin{abstract}
The architectural designs, especially the industrial buildings, have adopted, as a usual parameter of design, fixed criteria of square footage according to furniture or number of occupants per room. Projects destined to the industrial use also admit, as a guiding thread for its spatial configuration, the flow of the production elaborated from the tasks, thus neglecting the variability of the productive process and its evolution. This practice makes the workplace a dictum to which employees must adapt, impacting productivity and quality of production of goods and services, which in turn, generate financial losses to the institution. One of the problems found in the conception of architectural design is the difficulty of integrating, in practice, the functional quality expected in an Architectural Programming, to the project. In fact, it is considered as a priority, what is prescribed, that is, the task, disregarding the activity and the issues arising from it. This research is proposing an articulation of the concepts of Ergonomics to the practice of Architecture designs, aiming at a new approach when assuming the activity as the organizing element of the components of the space. For that was integrated as a research auxiliary tool the Ergonomic Analysis of Work in the process of elaborating the Architectural Programming. Then, the activities, inherent in the tasks of a Brazilian food industry, were systematically analyzed. The
\end{abstract}

ROCHA, D.; ABRAHÃO, J. Arquitetura e ergonomia: a atividade como eixo condutor de projeto. In: SIMPÓSIO BRASILEIRO DE QUALIDADE DO PROJETO NO AMBIENTE CONSTRUÍDO, 6., 2019, Uberlândia. Anais... Uberlândia: PPGAU/FAUeD/UFU, 2019. p. 49-61. DOI https://doi.org/10.14393/sbqp19006. 
results showed that the lack of analysis of the activities generated a disorganized flow in the production and a layout that hinders the flexibility of the spaces.

Keywords: Architecture, Ergonomic, Architectural Programming, Ergonomic Work Analysis.

\section{INTRODUÇÃO}

A investigação dos processos que ocorrem no espaço de trabalho, mostra-se como uma ferramenta preciosa na elaboração dos projetos arquitetônicos. A constatação da frágil referência sobre o trabalho real, consequente da carência de investigação das atividades (DANIELLOU, 1996), repercute na desconformidade dos projetos de arquitetura às reais necessidades dos usuários.

Desde a década de 1980, a prática de elaboração dos projetos arquitetônicos, tem adotado, como parâmetro usual de dimensionamento, critérios fixos de metragem quadrada de acordo com as tarefas que serão exercidas no ambiente (CHERRY, 1999; DUERK, 1993). Nos edifícios destinados aos serviços industriais, o parâmetro de projeto, via de regra, é definido de acordo com maquinário ou número de ocupantes para cada posto de trabalho, tendo como fio condutor para a configuração espacial, o fluxo da produção elaborado a partir das tarefas, desconsiderando, portanto, a variabilidade do processo e sua evolução (RABARDEL, 1995; TERSSAC, 1992).

Neste sentido, ao elaborar um projeto arquitetônico pensado sob uma ótica que não observa as variáveis da produção, contradizendo os requisitos de trabalho, o espaço torna-se um ditado ao qual os funcionários devem se adaptar, os edifícios industriais, geralmente, são vistos e projetados de maneira estática. A eficiência do sistema é então baseada na capacidade do pessoal de incorporar a restrição espacial, isso pode revelar-se altamente negativo em termos de trabalho individual e coletivo (HEDDAD, 2015), impactando na produtividade e na qualidade de produção de bens e serviços (WISNER et. al., 1984), que por sua vez, geram prejuízos financeiros à instituição.

É preciso, então, ter cautela na aceitação imediata de soluções que podem ter sido adequadas para outros projetos, mas que não são apropriadas para satisfazer as necessidades específicas da organização em questão. A definição precipitada de soluções na fase de elaboração do Programa de Necessidades Arquitetônico (PNA), instrumento balizador nas decisões de projeto em diferentes etapas da concepção do desenho arquitetônico (PATTERSON, 2010), torna-o um elo fraco do processo construtivo. Além do risco do projeto ter de ser alterado com mais frequência e de maneira mais radical. Isso custará tempo e dinheiro e, consequentemente, causará insatisfação das partes envolvidas (VOORDT \& WEGEN, 2013).

Neste prisma, a literatura é farta na proposta metodológica para definição do PNA apoiada sobretudo nas bases conceituais da tarefa, ou seja, no que é prescrito. Longe de subestimar a aproximação com a análise da tarefa no método adotado, uma vez que é a própria tarefa que sustenta as atividades, este artigo visa analisar as consequências de um PNA elaborado sem considerar a possibilidade de flexibilidade projetual e o reflexo disto nas condições de trabalho. Ao abordar a tarefa busca-se pela via da análise da atividade apreender os determinantes e condicionantes da tarefa. E são esses condicionantes e determinantes que retroalimentam o processo do PNA. 
Talvez aí resida o ineditismo desta abordagem, focada na atividade como meio de condução às demandas de projeto.

Considerando que toda e qualquer construção será ocupada por um determinado perfil de usuários e terão finalidades distintas, presume-se a importância do arquiteto conhecer as tarefas prescritas, que serão desenvolvidas no espaço construído, e sobretudo, as atividades cotidianas dos usuários dentro do ambiente à ser ocupado. Para tanto, sugere-se que recorra à cooperação multidisciplinar, uma vez que, é quase impossível se ter domínio de todas as variáveis envolvidas em um projeto arquitetônico (MARTIN, 2007).

Neste cenário, articulou-se, nesta pesquisa, os conceitos e métodos da Ergonomia aos métodos de concepção do projeto de Arquitetura. O objetivo de tal procedimento foi definir elementos de referência, visando contribuir sob outra perspectiva, no processo de elaboração do PNA. Sendo assim, buscouse na Análise Ergonômica do Trabalho (AET) a possibilidade de aproximação com a realidade de trabalho, frente a importância de definir parâmetros e metas que permitam fornecer subsídios aos arquitetos, no processo de elaboração do Programa de Necessidades Arquitetônico (PNA).

A demanda por este estudo parte de questionamentos a cerca dos limites do PNA, cujo, ao ser aplicado no processo de criação do projeto de arquitetura, muitas vezes, não se alcança a funcionalidade esperada. Principalmente, no tangente às edificações industriais, onde as sequencias das atividades são mais exigentes. Causando, assim, frustações tanto nos profissionais que se veem obrigados a alterar seus projetos com maior frequência, tanto nos clientes, que não têm suas expectativas atendidas.

Diante disto, por meio da articulação dos procedimentos e instrumentos da AET aos do PNA, esta pesquisa visa averiguar se é possível preencher as lacunas deste método de projeto, afim de alcançar as reais necessidades dos usuários em seu espaço de trabalho. Para tanto, foi aplicado o produto desta articulação de métodos, em um estudo de caso, uma indústria brasileira do ramo alimentício, que confrontada à necessidade de inserir novos produtos e maquinários em seu processo produtivo, depara-se com a falta de flexibilidade de seu espaço construído.

Outro ponto importante, são as ferramentas adotadas na análise dos projetos de edifícios industriais e na sistematização dos dados, permitindo uma apreciação do cenário atual e futuro. Além dessas considerações, a discussão do tema, tem sua importância para compreender o papel da ação ergonômica quando associada às questões de projetos de arquitetura.

Enquanto estudo empírico, espera-se contribuir para formulação de um procedimento com critérios e recomendações de investigação das atividades, que auxiliem a elaborar novos parâmetros de projeto respaldados no PNA, para projetos de mesma natureza.

\section{ERGONOMIA E O PROGRAMA DE NECESSIDADES ARQUITETÔNICO}

A crescente procura pela ergonomia aplicada à arquitetura, convoca os profissionais da área a refletirem sobre os métodos utilizados para soluções das demandas de seus projetos, principalmente, no que tange à funcionalidade de uma edificação. VOORDT \& WEGEN (2013) consideram uma das grandes problemáticas, atualmente, enfrentada pelos arquitetos, a dificuldade de 
integrar à prática, a qualidade funcional prevista em um programa de necessidades arquitetônico e, colocá-la em seus projetos.

A percepção da situação real do trabalho, proposto pela AET, na elaboração do PNA, faz deste, um instrumento de previsão para o desenvolvimento de projetos. Considerar a própria atividade como unidade de análise, viabiliza a oportunidade de ampliar a interação das situações e do espaço de trabalho, além de promover uma visão global, facultando a coleta de dados e suas resultantes quantitativas e qualitativas.

Compreender a estrutura interna da atividade permite interpretar a natureza dos problemas da forma como estes são tratados pelos operadores (THEUREAU, 1992). Portanto, entender o contexto no qual o sistema de trabalho está inserido, além de contribuir para a definição de suas particularidades, delimita a situação estudada e possibilita a coleta de dados que deverão subsidiar novas propostas de transformação das situações reais.

A maneira como o trabalho é organizado, como as tarefas são definidas e divididas pelas equipes e pela hierarquia, os horários de produção, os ritmos, as possibilidades para os integrantes das equipes delimitarem o escopo do seu trabalho com relação ao tempo e ao espaço, também são fundamentais para o processo de compreensão do trabalho, possibilitando atribuir ao espaço um papel importante como recurso de gerenciamento (HUBAULT, 2012).

Tal compreensão, parte dos princípios básicos da ergonomia, e contribui significativamente para enriquecer os conceitos iniciais do processo projetual do espaço construído, afim de que o edifício alcance a qualidade funcional adequada ao uso previsto. O estudo centrado na atividade real do trabalho, integrado ao conceito da variabilidade do processo produtivo e dos trabalhadores, diferencia a AET das demais abordagens de análise.

Assim, associar a abordagem ergonômica aos parâmetros do PNA pode contribuir para aprimorar suas diretrizes, propiciando soluções às demandas do projeto e suprindo as exigências de seus usuários. O pressuposto de participação dos atores da situação de trabalho, tanto na coleta e validação dos dados, como na consideração das intenções no processo produtivo, enriquece as instruções de definição do projeto arquitetônico, uma vez que o fluxo de produção influencia diretamente na configuração do leiaute (VOORDT \& WEGEN, 2013).

De acordo com ABRAHÃO et. al. (2009) o dimensionamento do espaço é resultante da atividade em função da natureza da tarefa, dos equipamentos, do mobiliário e das conjunturas dos elementos de conforto ambiental, referentes à iluminação, ventilação, temperatura etc. O caráter estrutural e articulador da atividade também contribui para a definição dos aspectos relativos às interações entre os trabalhadores e as unidades do espaço de trabalho. Esses elementos de análise permitem o conhecimento da relação de proximidade espacial ou de comunicação, oferecendo dados para as decisões de projeto quanto aos aspectos funcionais e de distribuição de áreas.

Neste sentido, adotar os conceitos e pressupostos da Ergonomia no processo de elaboração do PNA, considerando as situações reais, pode auxiliar os profissionais da arquitetura, a compreenderem as atividades a serem 
exercidas pelos usuários no espaço de trabalho, evitando situações conflitantes de projeto, que dificilmente seriam previstas, sob uma visão que não considera as variais do processo.

\section{MÉTODO}

Adotou-se como método, para esta pesquisa, a integração entre as abordagens do PNA e da AET. Foram selecionados os procedimentos e instrumentos inerentes a cada uma, e, adaptados para este estudo, guardados seus princípios básicos. A integração destes métodos de análise, visa verificar a contribuição da AET na elaboração do PNA, por meio da compreensão dos condicionantes da atividade.

As análises ergonômica e arquitetônica, foram conduzidas partindo-se de uma demanda, e estruturada ao longo da ação, de maneira singular, de acordo com cada etapa do processo. Visto que, a importância relativa à estas etapas, o que elas compreendem, as idas e vindas entre elas, são específicas de cada ação ergonômica (GUÉRIN et. al., 2001).

Nesta perspectiva, AET foi inserida ao Processo Construtivo, proposto por VOORDT e WEGEN (2013), e suas etapas foram delineadas de forma a subsidiar a coleta de dados associadas ao PNA. Com intuito de contemplar não apenas as atuais necessidades de operação, mas que também trouxesse no seu bojo, o conceito de flexibilidade que comportasse a implantação de novos produtos na indústria. A Figura 1 ilustra a integração das diferentes variáveis que modularam o método adotado neste estudo:

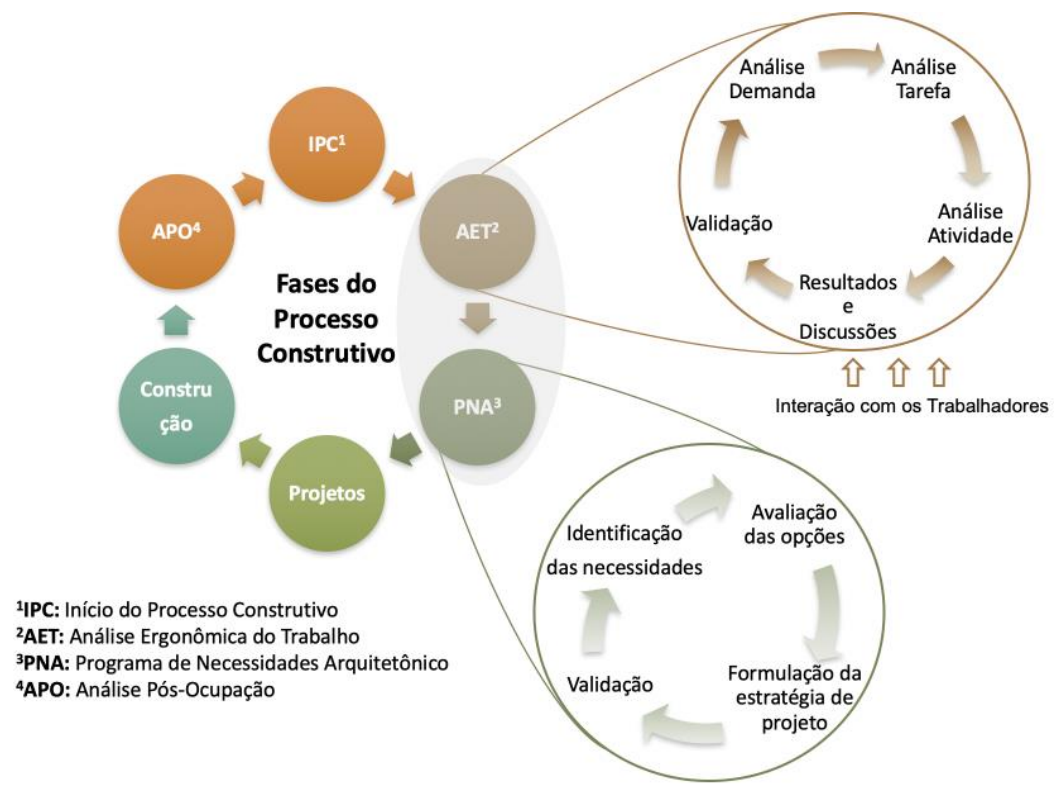

Figura 1 - Adaptação do Processo Construtivo proposto por Voordt e Wegen (2013): integrando a Análise Ergonômica do Trabalho (Guérin, 2001) ao Programa de Necessidades Arquitetônico proposto por Blyth e Worthington (2007) Fonte: Rocha (2019)

Foi assegurada, nesta pesquisa, a participação dos trabalhadores quando da coleta de dados, e na etapa de validação, como parte do processo de análise, em consonância com os métodos da AET (Guérin, 2001). 


\subsection{Caracterização do objeto empírico}

Criada em 1991, a indústria, que serviu como objeto desta pesquisa, localiza-se no interior do Estado de Goiás. Atualmente, ocupa o posto de maior processadora de gengibre do país. Sua gama de produto é composta por Cristais Salgado e Doce, Goma e Bala de gengibre.

Os diretores pretendem ampliar sua gama de produtos e, necessitam implantar novos equipamentos e maquinários ao processo produtivo, inserido em uma estrutura já existente. Assim, mesmo tendo espaço físico suficiente para tal objetivo, a empresa deparou-se com a dificuldade de implementar outro setor de produção em sua edificação.

\subsection{Procedimentos e Instrumentos}

Na coleta de dados foram utilizados instrumentos inerentes a AET e, em alguns momentos, articulados com instrumentos próprios do PNA. Esta análise foi dividida em seis etapas, conforme o método proposto na Figura 1:

- Análise da Demanda;

- Análise da Tarefa;

- Análise das Atividades;

- Tratamento dos dados;

- Validação;

- Formulação da estratégia de projeto.

\section{RESULTADOS}

Com objetivo de facilitar a compreensão dos fluxos e setores que compõem a indústria, foi desenvolvido o fluxograma dos produtos, setorização de seus departamentos e suas interligações, a partir dos dados obtidos nesta pesquisa, conforme ilustrado na Figura 2:

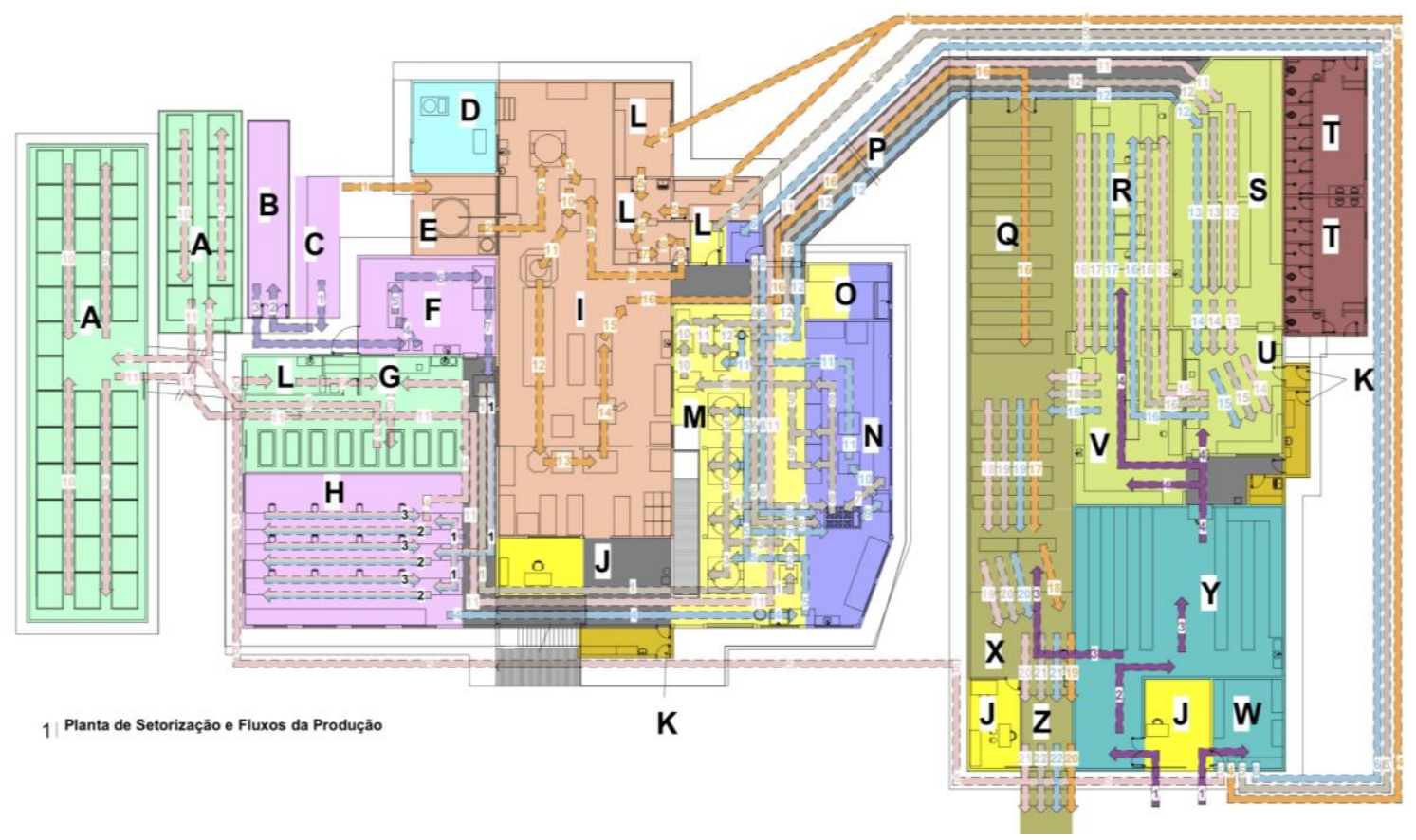

Figura 2 - Setorização e Fluxos da Produção.

Fonte: Rocha (2019) 
Quadro 1 - Ambientes da Indústria

\begin{tabular}{|l|l|l|l|}
\hline Setor & Descrição & Setor & Descrição \\
\hline A & Estufa Solar & B & Contêiner Refrigerado \\
\hline C & Descarregamento de Matéria-prima & D & Casa de Máquinas \\
\hline E & Estoque de Glucose & F & Sala de Higienização \\
\hline G & Sala de Salga & H & Sala de Corte de Gengibre \\
\hline I & Produção de Bala & J & Administração \\
\hline K & Acesso de Funcionários & L & Sala de preparo de insumos \\
\hline M & Produção de Goma & N & Produção Cristais Doce \\
\hline O & Sala de higienização de instrumentos & P & $\begin{array}{l}\text { Rampa de acesso para galpão de } \\
\text { embalagem }\end{array}$ \\
\hline Q & Estoque de produto acabado & R & Sala de Rotulagem \\
\hline S & Estoque de produto a ser envasado & T & $\begin{array}{l}\text { Sanitário e vestiário feminino } \\
\text { masculino }\end{array}$ \\
\hline U & Sala de envase & V & Sala de embalagem \\
\hline W & Estoque de insumos & Y & Estoque de embalagens \\
\hline
\end{tabular}

Fonte: Rocha 2019

Quadro 2 - Setorização

\begin{tabular}{|l|l|}
\hline \multicolumn{1}{|c|}{ Setor } & \multicolumn{1}{|c|}{ Descrição } \\
\hline & Produção de Bala \\
\hline & Matéria-prima (gengibre in natura) \\
\hline & Vestiários e Sanitários \\
\hline & Circulação \\
\hline & Produção de Cristais Doces \\
\hline & Estoque de embalagens e Insumos \\
\hline & Produção de Cristais Salgados \\
\hline & Casa de máquinas \\
\hline & Produção de Goma \\
\hline & Envase, Embalagem e Rotulagem \\
\hline & Estoque e expedição de Produtos acabados \\
\hline & Paramentação / DML' /Acesso aos Setores de produção \\
\hline & Administrativo \\
\hline
\end{tabular}

Fonte: Rocha 2019

Esta fase do método foi importante para a compreensão do contexto físico e organizacional da indústria, permitindo identificar os objetivos e metas das tarefas prescritas pela instituição. 
Quadro 3 - Fluxo da Produção

\begin{tabular}{|c|l|}
\hline Setor & \\
\hline 3 & Fluxo matéria-prima in natura \\
\hline 3 & Fluxo Cristais salgado \\
\hline 3 & Fluxo Cristais doce \\
\hline 3 & Fluxo Goma \\
\hline & Fluxo Bala \\
\hline & Fluxo embalagens e insumos \\
\hline
\end{tabular}

Fonte: Rocha 2019

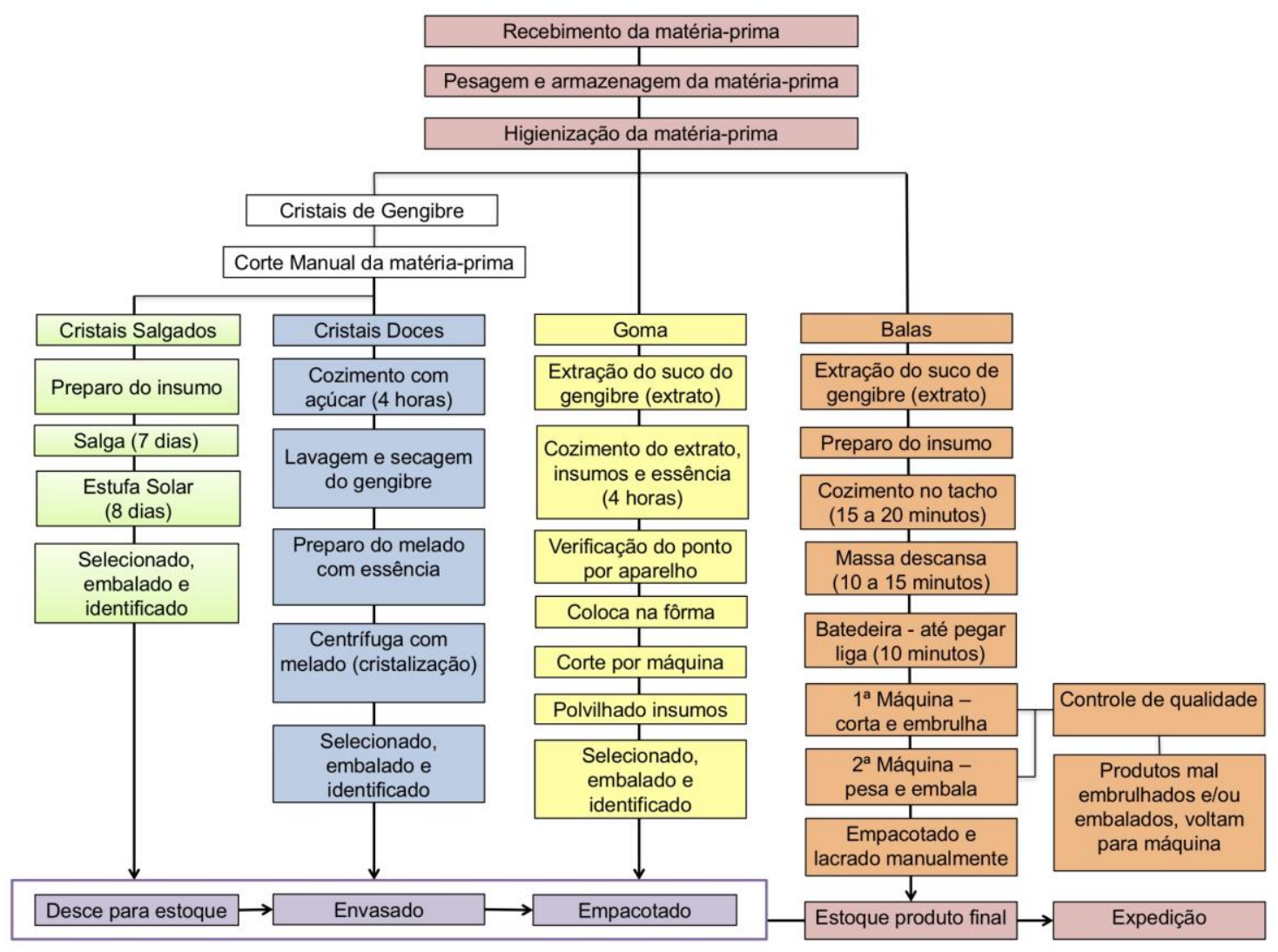

Figura 3 - Setorização e Fluxos da Produção.

Fonte: Rocha (2019)

A Figura 4, foi elaborada a partir das observações sistemáticas dos setores de produção que apresentaram maior conflito quanto aos fluxos de produtos e funcionários. A análise das atividades neste local possibilitou a constatação do emaranhado de fluxos que acontecem nos setores observados.

O processo de produção tal como foi concebido apresenta rupturas no fluxo produtivo consequência do leiaute, que não considerou as variáveis do processo de produção e, não prevê a evolução da indústria. Além disso, a distribuição dos setores de produção no espaço construído, não respeitam as interligações necessárias entre eles. Tal situação desfavorece os outros setores e, consequentemente, prejudica o fluxo da produção. 


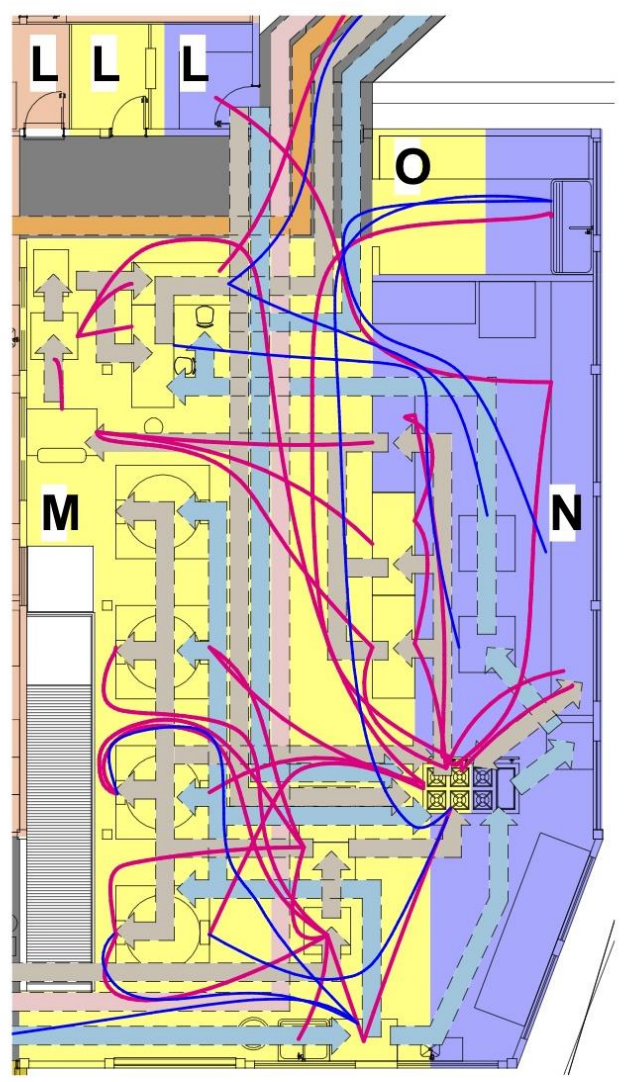

1 Planta de fluxos de funcionários e produtos - Setores de Goma e C. Doce

Figura 4 - Fluxograma do deslocamento dos funcionários e dos produtos nos setores de produção de cristais doce e goma**.

Fonte: Rocha (2019)

Quadro 4 - Movimentação dos Funcionários

\begin{tabular}{|l|l|}
\hline Setor & \multicolumn{1}{|c|}{ Descrição } \\
\hline & Movimentação do funcionário responsável pela produção de goma. \\
\hline & $\begin{array}{l}\text { Movimentação do funcionário responsável pela produção de cristais de } \\
\text { gengibre doce. }\end{array}$ \\
\hline
\end{tabular}

Fonte: Rocha 2019

A partir desta graficação (Figura 4), a qual considera as situações reais da produção, o projetista pode compreender as demandas tanto do trabalhador, como da organização e por meio de artifícios de projeto, apresentar soluções mais adequadas para o bom funcionamento da indústria.

Os dados obtidos nas análises realizadas nas instalações da indústria, permitiram a elaboração do programa de necessidades arquitetônico (Quadro 5), que se deu de forma evolutiva, a medida em que que são coletados os dados da organização, por meio de técnicas de análise, tais como as estabelecidas para este estudo.

** Legenda de ambientes ver Tabela 1 (página 6) e Tabela 2 (página 7);

** Legenda de Fluxo de produtos ver Tabela 3 (página 7);

** Legenda de Movimentação de funcionários ver Tabela 4 (página 8). 


\section{Quadro 5 - Programa de Necessidades Arquitetônico: para Indústria do Setor Alimentício - Processadora de gengibre.}

\begin{tabular}{|c|c|c|c|c|}
\hline & Objetivo & $\begin{array}{l}\text { Readequar projetc } \\
\text { necessárias entre o } \\
\text { produção, par }\end{array}$ & $\begin{array}{l}\text { arquitetônico, consider } \\
\text { ambientes, com intuito } \\
\text { integrar novos produtc } \\
\text { produção. }\end{array}$ & $\begin{array}{l}\text { do as interligações } \\
\text { otimizar o fluxo da } \\
\text { yo processo de }\end{array}$ \\
\hline Setor $^{2}$ & Função & $\begin{array}{l}\text { Interligação } \\
\text { necessária* }\end{array}$ & $\mathrm{N}^{\circ}$ de funcionários & Metragem (\%) \\
\hline & Produção de Bala & & 3 & 14 \\
\hline & Matéria-prima & & $\begin{array}{l}\text { Mesmos funcionários } \\
\text { cristais salgados }\end{array}$ & 10 \\
\hline & Sanitários & & 0 & 4 \\
\hline & Circulação & & 0 & $\begin{array}{l}\text { Estimada durante } \\
\text { projeto }\end{array}$ \\
\hline & $\begin{array}{c}\text { Produção de Cristais } \\
\text { Doces }\end{array}$ & & 1 & 12 \\
\hline & $\begin{array}{l}\text { Estoque de } \\
\text { embalagens e } \\
\text { Insumos }\end{array}$ & & $\begin{array}{l}\text { Mesmos funcionários } \\
\text { administrativo }\end{array}$ & 3 \\
\hline & $\begin{array}{c}\text { Produção de Cristais } \\
\text { Salgados }\end{array}$ & & 5 & 15 \\
\hline & Casa de máquinas & & 0 & 2 \\
\hline & Produção de Goma & & 1 & 12 \\
\hline & $\begin{array}{c}\text { Envase, Embalagem } \\
\text { e Rotulagem }\end{array}$ & & 3 & 12 \\
\hline & $\begin{array}{c}\text { Estoque e } \\
\text { expedição de Prod. } \\
\text { final }\end{array}$ & & $\begin{array}{l}\text { Mesmos funcionários } \\
\text { administrativo }\end{array}$ & 11 \\
\hline & $\begin{array}{l}\text { Paramentação/ } \\
\text { Limpeza }\end{array}$ & & 2 & 3 \\
\hline & Administrativo & $\begin{array}{c}\text { Acessos desejáveis } \\
\text { (Fig. 13) }\end{array}$ & 3 & 2 \\
\hline & Total: & & 18 & 100 \\
\hline
\end{tabular}

Fonte: ROCHA 2019

Os dados do dimensionamento, apresentado na Quadro 5, foi feito com base na estrutura existente da indústria.

As atividades desenvolvidas nos diversos setores da indústria influenciam nos condicionantes dos aspectos físicos do ambiente de trabalho. A identificação da necessária relação de proximidade entre os setores, a qual influencia diretamente a malha do fluxo da produção, permitiu a construção do Organograma espacial e fluxograma da indústria (Figura 5):

\footnotetext{
2 Ver legenda de ambientes na Tabela 4 (página 73).
} 


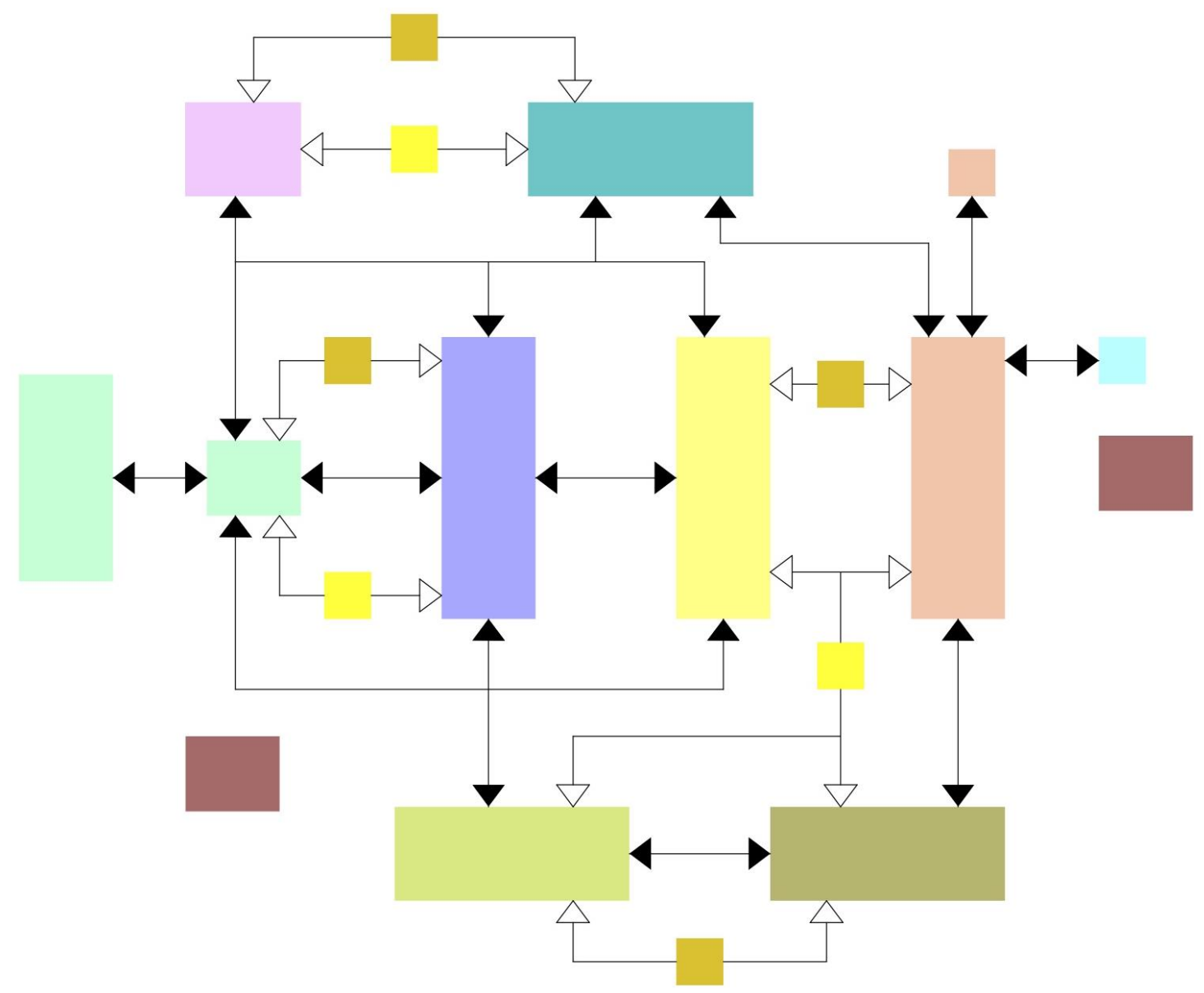

Ligação direta necessária
Ligação direta desejável

Figura 5 - Organograma espacial e Fluxograma da produção propostos.

Fonte: Rocha (2019)

O agrupamento dos setores com mesma natureza de atividade permitiu um fluxo contínuo e mais ordenado. O projeto quando desenvolvido priorizando as atividades, auxilia no entendimento imediato do funcionamento da organização, assimilando o espaço à tarefa, facilitando a realização das atividades e tomadas de decisão durante o processo produtivo.

Ao adotar um partido arquitetônico modular, conforme o organograma apresentado (Figura 5), também facilita a inserção de novos setores de produção que podem seguir a linha de projeto, possibilitando conexões entre os setores de produção, sem interferências no fluxo produtivo.

Os resultados apontaram que as interrupções do fluxo produtivo resultaram em discordâncias no projeto arquitetônico, o qual não acompanhou a evolução da indústria. A disposição dos diversos setores da indústria, não atendem as interligações necessárias, desfavorecendo as etapas e o fluxo da produção, os quais apresentam-se confusos e, com consequência negativa no desempenho da produtividade. 


\section{CONCLUSÃO}

Ao considerar a realidade do processo produtivo as chances de suprir as reais necessidades dos usuários em atividade em uma a edificação, é ampliada, uma vez que, permite que o projeto arquitetônico abarque, acima de tudo, a variabilidade humana e os diferentes pontos de vista dos participantes do sistema de trabalho. É possível articular os conceitos e métodos da ergonomia aos procedimentos utilizados na programação arquitetônica, enriquecendo o meio de subsidiar a prática de projeto.

Nesta perspectiva, a integração do método ergonômico de investigação da atividade, a Análise Ergonômica do Trabalho (AET), ao processo de elaboração do Programa de Necessidades Arquitetônico (PNA, assume a atividade como o elemento organizador dos componentes do espaço construído. Tal integração proporciona o enriquecimento do PNA quanto aos dados das situações reais da organização envolvida, subsidiando, assim, a prática de projeto arquitetônico.

A participação dos trabalhadores, no processo de coleta de dados, foi fundamental para compreensão das atividades realizadas por cada setor da indústria, possibilitando identificar as inadequações de configuração do espaço com consequências no fluxo produtivo. As interfaces conceituais e metodológicas da ergonomia e da arquitetura investigadas neste estudo significam o preenchimento de lacunas para elaboração do Programa de Necessidades Arquitetônico.

A natureza aberta do método da AET, ao mesmo tempo em que trata da singularidade do objeto estudado permitiu que, as particularidades encontradas nas atividades dos trabalhadores da indústria, também, fossem contemplado no PNA. Nesta perspectiva, a AET corroborou como uma ferramenta determinante na transformação do trabalho, refletindo nas decisões de configuração espacial, tanto para situação atual como em uma ação futura.

Diante disto, o método da ação ergonômica contribuiu para a formulação do problema do projeto e o seu ajuste às metas estabelecidas. Estes procedimentos permitiram a retroalimentação de dados, integrando elementos da atividade que dificilmente seriam contemplados no projeto a partir de uma abordagem restrita de uma única área do conhecimento. Em contrapartida, a arquitetura também contribui na ação ergonômica, uma vez que, o espaço construído mostra-se como um recurso de gerenciamento de trabalho.

\section{REFERÊNCIAS}

ABRAHÃO, J., SZNELWAR, L., SILVINO, A., SARMET, M., PINHO, D. Introdução à ergonomia da prática à teoria. Blucher, São Paulo (2009).

BLYTH, A., WORTHINGTON, J. Managing the brief for better design. Spon Press, Oxon (2007).

CHERRY, E. Programming for design: from theory to practice. Wiley, New York (1999). 
DANIELLOU, F. Questões epistemológicas levantadas pela ergonomia de projeto. In: DANIELLOU, F. (coord.) A ergonomia em busca de seus princípios, pp. 181-198. Blücher, São Paulo (1996).

DUERK, D. P. Architectural programming: Information management for design. New York: Wiley (1993).

HEDDAD, N. The collective construction of space and activity dynamics, a performance issue. Proceedings 19th Triennial Congress of the IEA, Melbourne 9-14 (2015).

HUBAULT, F. Ergonomia e condução de projeto arquitetônico. In: Abrahão. J., et al.: Cadernos de trabalho, tecnologia e organização, pp.51-103. Blucher, São Paulo (2012).

MARTIN, C. O ergonomista nos projetos arquitetônicos. In: Falzon, P. (Ed.) Ergonomia, pp. 357-369. Blücher, São Paulo (2007).

GUÉRIN. F., et al. Compreender o trabalho para transformá-lo: a prática da ergonomia. Blücher, São Paulo (2001).

PATTERSON, C. Ergonomia e Arquitetura: interfaces na elaboração de programas arquitetônicos. In: Abrahão, J. (coord.) Mestrado em Psicologia Social, do Trabalho e das Organizações - Instituto de Psicologia, (2010), vol. 229 f. Universidade de Brasília, Brasília (2010).

RABARDEL, P. Les hommes et les technologies: une approche cognitive des instruments contemporains. Paris: Armand Colin, 1995.

TERSSAC, G. Le travail organisé: faut-il repenser le travail? Actes du XXX Congrès de la Société d'Ergonomie de Langue Française, Biarritz, França, 5-9 (1995).

THEUREAU , J. Le cours d'action analyse semio-logique. Peter Lang: Neufchatel (1992).

VOORDT, T, WEGEN, H. Arquitetura sob o olhar do usuário. Programa de necessidades, projeto e avaliação de edificações. Oficina de Textos, São Paulo (2013).

WISNER, A., DANIELLOU, F., PAVARD, B., PINSKI, L., \& THEUREAU, J. Place of work analysis in software design. In: G. Salvendy (Org.), Human-computer interacion. Amsterdam: Elsevier (1984). 